International Journal of

Environmental Research and

Public Health

ISSN 1660-4601

www.mdpi.com/journal/ijerph

Article

\title{
Exposures of 129 Preschool Children to Organochlorines, Organophosphates, Pyrethroids, and Acid Herbicides at Their Homes and Daycares in North Carolina
}

\author{
Marsha K. Morgan ${ }^{1}{ }^{*}$, Nancy K. Wilson ${ }^{2}$ and Jane C. Chuang ${ }^{3}$ \\ 1 National Exposure Research Laboratory, United States Environmental Protection Agency, \\ 109 T.W. Alexander Drive, Research Triangle Park, NC 27709, USA \\ 2 Battelle, Durham, NC 27713, USA; E-Mail: njkwilson@nc.rr.com \\ 3 Battelle, Columbus, OH 43201, USA; E-Mail: ccjane20@ hotmail.com \\ * Author to whom correspondence should be addressed; E-Mail: morgan.marsha@epa.gov; \\ Tel.: +1-919-541-2598; Fax: +1-919-541-0905.
}

Received: 10 February 2014; in revised form: 21 March 2014 / Accepted: 24 March 2014 / Published: 3 April 2014

\begin{abstract}
Few data exist on the concurrent exposures of young children to past-use and current-use pesticides in their everyday environments. In this further analysis of study data, we quantified the potential exposures and intake doses of 129 preschool children, ages 20 to 66 months, to 16 pesticides (eight organochlorines, two organophosphates, three pyrethroids, and three acid herbicides). Environmental samples (soil, dust, outdoor air, and indoor air) and personal samples (hand wipes, solid food, and liquid food) were collected at 129 homes and 13 daycare centers in six counties in North Carolina between 2000 and 2001. $\alpha$-Chlordane, $\gamma$-chlordane, heptachlor, chlorpyrifos, diazinon, cis-permethrin, trans-permethrin, and 2,4-dichlorophenoxyacetic acid (2,4-D) were detected $\geq 50 \%$ in two or more media in both settings. Of these pesticides, the children's estimated median potential intake doses through dietary ingestion, nondietary ingestion, and inhalation routes were the highest for 2,4-D and cis/trans-permethrin (both $4.84 \mathrm{ng} / \mathrm{kg} / \mathrm{day}$ ), cis/trans-permethrin (2.39 ng/kg/day), and heptachlor (1.71 ng/kg/day), respectively. The children's estimated median potential aggregate intake doses by all three routes were quantifiable for chlorpyrifos (4.6 ng/kg/day), cis/trans-permethrin (12.5 ng/kg/day), and 2,4-D (4.9 ng/kg/day). In conclusion, these children were likely exposed daily to several pesticides from several sources and routes at their homes and daycares.
\end{abstract}


Keywords: children; pesticides; exposure; intake dose; residences; daycare centers

\section{Introduction}

Since the 1950s, a number of commercial products containing pesticides have been used to kill insects and weeds in residential and agricultural settings in the United States (U.S.). Some of the major classes of insecticides that have been applied to control insects in these settings include the organochlorine (OC), organophosphorus (OP), and pyrethroid (PY) insecticides. For the OC insecticides (i.e., aldrin, chlordane, DDT, dieldrin, endrin, heptachlor, and lindane), the U.S. Environmental Protection Agency (U.S. EPA) has phased-out almost all uses since the late-1980s because they are persistent and bioaccumulative in the body [1-6]. The OP insecticides, particularly chlorpyrifos and diazinon, are still commonly applied on agricultural crops. However, the U.S. EPA phased-out almost all residential and other similar uses of chlorpyrifos and diazinon at the end of 2001 and 2004, respectively, to reduce children's exposures and potential health risks [7,8]. The PY insecticides (e.g., permethrin and cyfluthrin) have replaced many of the residential uses of the OP insecticides, and they are also extensively applied on agricultural fields [9]. Lastly, one of the major classes of herbicides widely used to kill unwanted weeds on lawns, pastures, and croplands have been the acid (AC) herbicides, and frequently applied ones today include dicamba and 2,4-D [10-13].

Only a few published studies have reported concurrent levels of the OC, OP, and PY insecticides and the AC herbicides in several media at children's homes and daycare centers in the U.S. [14,15]. Wilson et al. [14] reported measureable concentrations of aldrin, $\alpha$-chlordane, $\gamma$-chlordane, $p, p$ '-DDT, dieldrin, endrin, heptachlor, lindane, chlorpyrifos, diazinon, and 2,4-D in multimedia samples collected at 10 child daycare centers in North Carolina (NC) in the spring 1997. In a proceeding study, Wilson et al. [15] also showed measureable levels of these same 11 pesticides in multimedia samples collected at the homes and daycare centers of nine preschool children in NC in the summer of 1997. In the Wilson et al. [15] study, the children's estimated median potential aggregate intake doses to these pesticides ranged from $0.15 \mathrm{ng} / \mathrm{kg} /$ day (endrin) to $87.6 \mathrm{ng} / \mathrm{kg} /$ day $(2,4-\mathrm{D})$. This research suggests that young children are likely being exposed to several pesticides, including past-use ones, on a daily basis in their everyday environments.

In 1999, the U.S. EPA designed the Children's Total Exposure to Persistent Pesticides and Other Persistent Organic Pollutants (CTEPP) study in part to fill critical data gaps on young children's exposures to pesticides in direct response to the Food Quality Protection Act (FQPA) of 1996 [16,17]. The FQPA of 1996 specifically mandated that the US EPA consider the aggregate exposures and cumulative health risks of infants and children before setting pesticide tolerances in food [16]. The CTEPP study was built upon the data and information obtained in the earlier pilot studies conducted by Wilson et al. $[14,15]$. The CTEPP study is the first large-scale study in the U.S. to quantitatively assess preschool children's exposures to a number of pesticides, including past-use one, from several sources and routes of exposure [17]. It investigated the exposures of 256 preschool children (ages 20-67 months) to over 40 chemicals, including pesticides, commonly found at their homes and daycare centers in North Carolina (NC, U.S.) and Ohio (OH, U.S.). 
In previous publications [18-21], we examined separately the CTEPP children's potential exposures and potential intake doses to four current-use pesticides (i.e., chlorpyrifos, diazinon ( $\mathrm{OH}$, only), 2,4-D, and/or permethrin $(\mathrm{OH}$, only $))$ in media at their homes and/or daycare centers in $\mathrm{NC}$ and $\mathrm{OH}$. In this present work, we conducted a further analysis of the study data that investigated the CTEPP children's concurrent exposures to nine past-use pesticides (aldrin, $\alpha$-chlordane, $\gamma$-chlordane, $p, p$ '-DDT, dieldrin, endrin, heptachlor, lindane, 2,4,5-trichlorophenoxyacetic acid (2,4,5-T)) and seven current-use pesticides (chlorpyrifos, diazinon, cyfluthrin, cis-permethrin, trans-permethrin, dicamba, and 2,4-D) in media at their homes and daycare centers in NC. For this analysis, we examined the demographic data, questionnaire data, environmental measurement data, and personal measurement data for the subset of 129 children that participated in the NC component of the study. The objectives were to quantify the distributions of 16 different pesticides in several environmental and personal media for a subset of CTEPP children at their homes and daycares in NC, to estimate the children's potential exposures and potential intake doses to the pesticides by the dietary, nondietary, and inhalation routes of exposure, and to identify the major sources and exposure routes.

\section{Methods}

\subsection{Study Cohort}

The study design for the CTEPP study has been discussed in-depth by Wilson et al. [17]. Briefly, the participants were recruited from six counties in NC from July 2000 to April 2001 and from six counties in $\mathrm{OH}$ from April 2001 to November 2001. The study cohort consisted of 256 preschool children; 129 children participated from NC and 127 children participated from $\mathrm{OH}$. In NC, 66 children stayed-at-home with their adult caregivers during the day and 63 children attended daycare during the day. In OH, 69 children stayed-at-home with their adult caregivers during the day and 58 children attended daycare during the day. For the daycare group of children, environmental and personal samples were collected at both their homes and daycare centers. Environmental samples (soil, dust, outdoor air, and indoor air) and personal samples (hand wipes, solid food, and liquid food) were collected over a 48-h monitoring period at 129 homes and 13 daycare centers in NC and at 127 homes and 16 daycare centers in $\mathrm{OH}$. Field staff collected environmental samples at both locations, and adult caregivers (i.e., parents and daycare teachers) collected personal samples from the children.

\subsection{Human Subjects Review}

The CTEPP study was a human observational research study, as defined in 40 Code of Federal Regulations, Part 26.402 [22]. The study protocol and procedures used to obtain informed consent of the adult caregivers and the assent of the preschool children were approved by an independent institutional review board (Battelle) before beginning the study and complied with all applicable requirements of the Common Rule regarding additional protections for children (Subpart D). The study protocol and procedures were also approved by the US EPA's Human Subjects Research Official prior to starting the study. 


\subsection{Field Sampling}

Detailed descriptions of the field sampling activities that occurred over a 48-h monitoring period at the children's homes and/or daycare centers have been described in Wilson et al. [17]. The collection of the environmental samples and personal samples are briefly described below. Soil samples consisted of scraping the surface of a $0.1 \mathrm{~m}^{2}$ area of bare soil with a putty knife (nearest a child's play area) and placing it into a pre-cleaned glass jar. Indoor floor dust samples were collected from a $0.76 \mathrm{~m}^{2}$ of carpeting from the child's main activity area (e.g., living room or classroom) with a high volume surface sampler (Cascade Stack Sampling Systems, Bend, OR, USA) and transferring the sample to a pre-cleaned glass jar. Outdoor air was sampled over a 48-h period using a URG-2000 cartridge with a Thomas pump generating a flow rate of $\sim 4.0 \mathrm{~L} / \mathrm{min}$. For indoor air, 48-h samples were collected using a URG-2000 cartridge with a SKC pump $(\sim 4.0 \mathrm{~L} / \mathrm{min})$ in the child's main activity area. Hand wipe samples consisted of the adult caregivers wiping the front and back of both hands of the children with a $100 \mathrm{~cm}^{2}$ pre-wetted cotton pad (SOF-WICK, Johnson and Johnson, Arlington, TX, USA) with $2 \mathrm{~mL}$ of $75 \%$ isopropanol and placing it into a pre-cleaned glass jar. Duplicate diet samples were collected from each child by their adult caregiver over the 48-h period; solid and liquid food samples were collected separately in $2 \mathrm{~L}$ pre-cleaned glass jars. Solid foods included all the fruits, vegetables, meats, dairy products, and desserts eaten by each child. Liquid foods included all of the beverages, excluding drinking water, consumed by each child. Examples of typical solid foods collected were apples, bananas, carrots, lunch meats, cheeses, and cookies, and examples of typical liquid foods collected were fruit juices, milk, and soft drinks. Duplicate amounts of solid and liquid foods were collected at homes, and duplicate serving of solid and liquid foods were collected at daycares. All samples were kept at reduced temperatures in coolers until picked up by field staff.

\subsection{Sample Analyses}

Detailed extraction and analytical procedures for the target pesticides in the environmental media and personal media can be found in Morgan et al. [18]. Briefly, the extraction methods for the OC, OP, and PY insecticides in each medium are as follows: soil samples $(2 \mathrm{~g})$ and dust samples $(0.5 \mathrm{~g})$ were sonicated with $10 \%$ diethyl ether in hexane, "concentrated" by Kuderna-Danish (KD) evaporation, followed by Florisil solid phase extraction (SPE), and concentrated again. Air samples and wipe samples were Soxhlet-extracted ( 14-h) with dichloromethane (DCM), concentrated and subjected to Florisil SPE clean-up (if needed). Solid food samples were homogenized by a food chopper, and then $12 \mathrm{~g}$ of food were mixed with Extrelute and extracted using accelerated solvent extraction (ASE) with DCM, concentrated, and fractionated by gel permeation chromatography (GPC) with DCM, followed by an ENVI-Carb clean up. Liquid food samples $(30 \mathrm{~mL})$ were refluxed with DCM, filtered, concentrated, and then GPC clean-up with DCM. All sample extracts were adjusted to $1 \mathrm{~mL}$ with solvent and placed into glass vials. The extraction methods for the AC herbicides in each medium are as follows: soil samples $(5 \mathrm{~g})$ were mixed with Extrelute, extracted using ASE with acetone, and concentrated. Dust samples $(0.5 \mathrm{~g})$ were mixed with sand, then extracted using ASE with acetone, and concentrated. Air samples and hand wipe samples were Soxhlet-extracted with acetonitrile and concentrated. Solid food samples were homogenized with a food chopper and $8 \mathrm{~g}$ were mixed with 
extrelute and extracted using ASE with methanol, and concentrated. Liquid food samples $(10 \mathrm{~mL})$ were mixed with Extrelute and extracted using ASE with methanol, and concentrated. All extracts were reduced to $1 \mathrm{~mL}$ with solvent, derivatized with $\mathrm{N}$-(tert-butyldimethylsilyl)-N-methyltrifluoroacetamine, and placed into glass vials.

The surrogate recovery standard used for the OC, OP, and PY insecticides was $p, p^{\prime}-D_{D E}-\mathrm{d}_{4}$. The internal standards for the three classes of insecticides were phenanthracene- $\mathrm{d}_{10} / p, p^{\prime}$ '-dibromobiphenyl, diazinon- $\mathrm{d}_{10}$, and $p, p^{\prime}$-dibromobiphenyl, respectively. The surrogate recovery standard for the AC herbicides was 2,4-D-C $\mathrm{C}_{13}$, and the internal standard was dicamba- $\mathrm{d}_{3}$. Matrix spikes were used for each target pesticide in all sampled media. All extracts were analyzed by a gas chromatograph with mass selective detection (6890/5973A Hewlett-Packard) in the selected ion monitoring (SIM) mode. Table 1 provides the estimated limits of detection (LODs) for the target pesticides in the environmental media and personal media. The estimated limit of detection (LOD) was defined "as the minimum analyte level detected in a sample (in a given medium) and was estimated to be one-half the limit of quantification (LOQ)" [23]. The estimated LOQ was about twice the LOD for each pesticide by matrix.

\subsection{Quality Assurance and Quality Control}

Field blanks for the pesticides were below the LODs in all media, except for chlorpyrifos and cis-permethrin in only 1 of 12 air samples each. The mean values of these two insecticides were below the LODs in the air samples, so no background corrections were made. Laboratory blanks for all pesticides were below the LODs in each sampled media. Relative percent differences between duplicate samples (aliquots of the same sample) for the target pesticides were less than $10 \%$ in all media, except for chlorpyrifos in the air samples (24\%) and dust/soil samples (14\%). Relative percent differences between the analytical duplicates (aliquots of the same sample extract) for the target pesticides were less than $8 \%$ in the sampled media. The mean recoveries for the surrogate recovery standards, $p, p^{\prime}-\mathrm{DDE}-\mathrm{d}_{4}$ and $2,4-\mathrm{D}-\mathrm{C}_{13}$, were between $73 \%$ and $100 \%$ and $75 \%$ and $91 \%$, respectively, in all media. The matrix spikes for the OC, OP, and PY insecticides had mean recoveries in media from $71 \%-130 \%$, except for diazinon (54\%) and cyfluthrin (64\%) in the liquid food samples and diazinon (58\%) in the solid food samples. For the AC herbicides, the matrix spikes had mean recoveries in all media between $72 \%$ and $99 \%$, except for the indoor and outdoor air samples $(64 \%-69 \%)$.

\subsection{Statistical Analyses}

Data values below the LOD were assigned the value of the LOD divided by the square root of two, except for the liquid food concentration data. Since the pesticide concentrations in the liquid food samples were barely detectable on the gas chromatographs, a more conservative value of LOD divided by the square root of 10 was used [18]. Descriptive statistics (frequency of detection, percentiles (50th and 95th), and range) were computed for the pesticides in each medium at both the homes and daycare centers. 
Table 1. Estimated limits of detection (LODs) for the target pesticides in environmental and personal media ${ }^{\mathbf{a}}$.

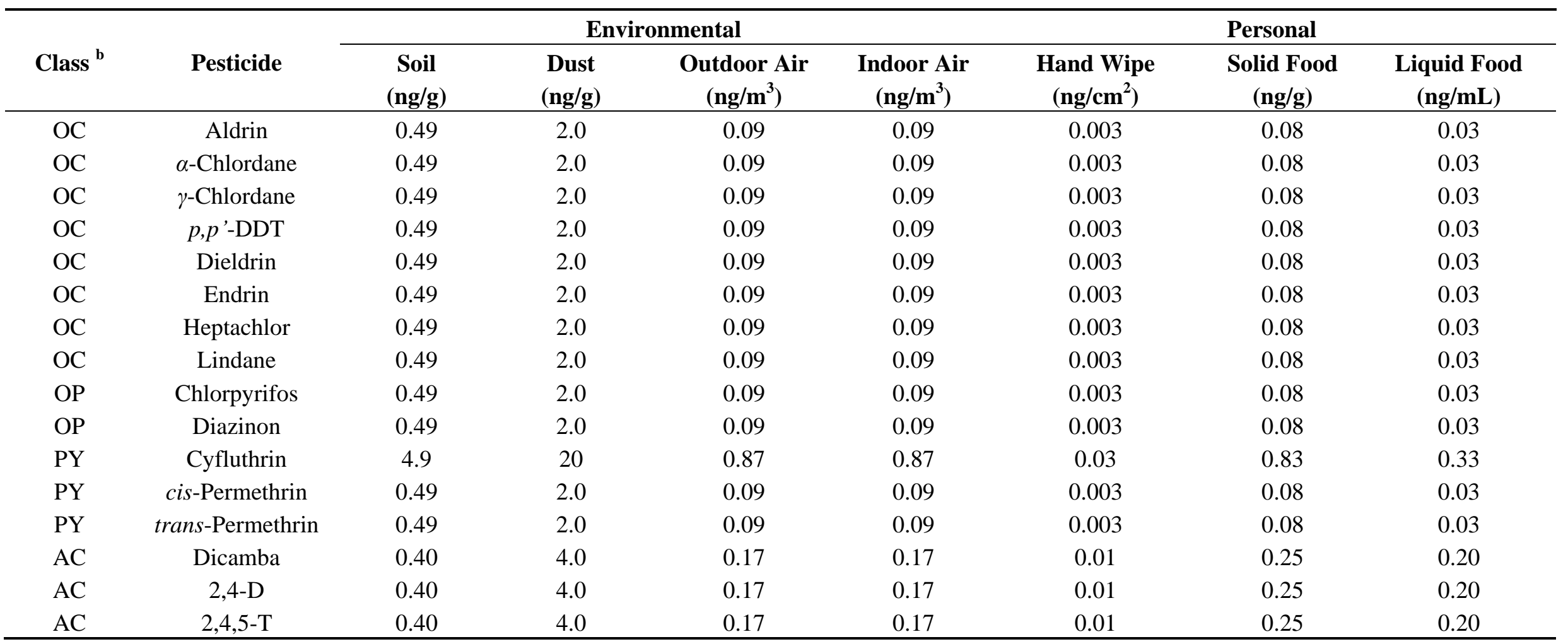

Notes: ${ }^{\text {a }}$ The estimated limit of quantification (LOQ) was about twice the reported LOD for a pesticide in each sample medium; ${ }^{\mathbf{b}}$ Pesticide classes include organochlorine insecticides (OC), organophosphorus insecticides (OP), pyrethroid insecticides (PY), and AC herbicides. 
Table 2. Equations used to calculate the children's estimated potential exposures to a pesticide by the dietary, nondietary, and inhalation exposure routes $^{\mathbf{a}, \mathbf{b}}$.

\begin{tabular}{|c|c|}
\hline Equation & Variable Definitions \\
\hline \multicolumn{2}{|l|}{ Dietary Ingestion Route } \\
\hline \multirow{10}{*}{$E_{\text {dietary }}=\frac{\left[\left(C_{d l} \times M_{d l}\right)+\left(C_{d s} \times M_{d s}\right)+\left(C_{h l} \times M_{h l}\right)+\left(C_{h s} \times M_{h s}\right)\right]}{N_{f}}$} & $\mathrm{E}_{\text {dietary }}=$ Maximum potential absorbed dose of each child over a day (ng/day) \\
\hline & $\mathrm{C}_{\mathrm{dl}}=$ Level of pesticide in the liquid food sample at daycare $(\mathrm{ng} / \mathrm{mL})$ \\
\hline & $\mathrm{C}_{\mathrm{hl}}=$ Level of pesticide in the liquid food sample at home $(\mathrm{ng} / \mathrm{mL})$ \\
\hline & $\mathrm{C}_{\mathrm{ds}}=$ Level of a pesticide in the solid food sample at daycare $(\mathrm{ng} / \mathrm{g})$ \\
\hline & $\mathrm{C}_{\mathrm{hs}}=$ Level of a pesticide in the solid food sample at home (ng/g) \\
\hline & $\mathrm{M}_{\mathrm{dl}}=$ Total volume of the liquid food sample at daycare $(\mathrm{mL})$ \\
\hline & $\mathrm{M}_{\mathrm{hl}}=$ Total volume of the liquid food sample at home $(\mathrm{mL})$ \\
\hline & $\mathrm{M}_{\mathrm{ds}}=$ Total weight of the solid food sample collected at daycare $(\mathrm{g})$ \\
\hline & $\mathrm{M}_{\mathrm{hs}}=$ Total weight of the solid food sample collected at home $(\mathrm{g})$ \\
\hline & $\mathrm{N}_{\mathrm{f}}=$ Number of days food samples were collected for each child (day) \\
\hline \multicolumn{2}{|c|}{ Nondietary Ingestion Route } \\
\hline \multirow{11}{*}{$E_{\text {nondietary }}=\frac{\left[\left(D_{d d} \times M_{d} \times t_{d i}\right)+\left(D_{d s} \times M_{s} \times t_{d o}\right)+\left(D_{d s} \times M_{d} \times t_{h i}\right)+\left(D_{h s} \times M_{s} \times t_{h o}\right)\right]}{t_{d i}+t_{d o}+t_{h i}+t_{h o}}$} & $E_{\text {nondietary }}=$ Maximum potential absorbed dose of each child over a day (ng/day) \\
\hline & $\mathrm{D}_{\mathrm{dd}}=$ Level of pesticide in the dust sample at daycare $(\mathrm{ng} / \mathrm{g})$ \\
\hline & $\mathrm{D}_{\mathrm{hd}}=$ Level of pesticide in the dust sample at home (ng/g) \\
\hline & $D_{d s}=$ Level of pesticide in the soil sample at daycare $(\mathrm{ng} / \mathrm{g})$ \\
\hline & $\mathrm{D}_{\mathrm{hs}}=$ Level of pesticide in the soil sample at home (ng/g) \\
\hline & $\mathrm{t}_{\mathrm{di}}=$ Time spent inside at daycare $(\mathrm{h} /$ day $)$ \\
\hline & $t_{h i}=$ Time spent inside at home (h/day) \\
\hline & $\mathrm{t}_{\mathrm{do}}=$ Time spent outside at daycare (h/day) \\
\hline & $t_{\mathrm{ho}}=$ Time spent outside at home (h/day) \\
\hline & $\mathrm{M}_{\mathrm{d}}=$ Estimated dust ingestion rate $(\mathrm{g} /$ day $)$ \\
\hline & $\mathrm{M}_{\mathrm{s}}=$ Estimated soil ingestion rate ( $\mathrm{g} /$ day) \\
\hline
\end{tabular}


Table 2. Cont

Equation

\begin{tabular}{c}
\hline Equation \\
\hline Inhalation Route ${ }^{\mathbf{c}}$ \\
$E_{\text {inhalation }}=\frac{\left[\left(C_{d i} \times t_{d i}\right)+\left(C_{d o} \times t_{d o}\right)+\left(C_{h i} \times t_{h i}\right)+\left(C_{h o} \times t_{h o}\right)+\left(C_{\text {away }} \times t_{\text {away }}\right)\right] \times V}{t_{d i}+t_{d o}+t_{h i}+t_{h o}+t_{\text {away }}}$
\end{tabular}

Variable Definitions

$\mathrm{E}_{\text {inhalation }}=$ Maximum potential absorbed dose of each child over a day (ng/day)

$\mathrm{C}_{\mathrm{di}}=$ Level of pesticide in the indoor air sample at daycare $\left(\mathrm{ng} / \mathrm{m}^{3}\right)$

$\mathrm{C}_{\mathrm{hi}}=$ Level of a pesticide the indoor air sample at home $\left(\mathrm{ng} / \mathrm{m}^{3}\right)$

$\mathrm{C}_{\mathrm{do}}=$ Level of a pesticide in the outdoor air sample at daycare $\left(\mathrm{ng} / \mathrm{m}^{3}\right)$

$\mathrm{C}_{\mathrm{ho}}=$ Level of a pesticide in the outdoor air sample at home $\left(\mathrm{ng} / \mathrm{m}^{3}\right)$

$\mathrm{C}_{\text {away }}=$ Indoor air level of pesticide at places away from daycare or home $\left(\mathrm{ng} / \mathrm{m}^{3}\right)$

$\mathrm{t}_{\mathrm{di}}=$ Time spent inside at daycare ( $\mathrm{h} /$ day)

$\mathrm{t}_{\mathrm{hi}}=$ Time spent inside at home (h/day)

$\mathrm{t}_{\mathrm{do}}=$ Time spent outside at daycare (h/day)

$t_{h o}=$ Time spent outside at home (h/day)

$\mathrm{t}_{\text {away }}=$ Time spent inside at places away from daycare or home (h/day)

$\mathrm{V}=$ Estimated ventilation rate $\left(\mathrm{m}^{3} /\right.$ day $)$

Notes: ${ }^{\mathbf{a}}$ The estimated potential intake dose of a child was calculated by dividing $\mathrm{E}_{\text {dietary, }} \mathrm{E}_{\text {nondietary }}$ or $\mathrm{E}_{\text {inhalation }}$ by their body weight (kg) and a default absorption rate of $50 \%$;

${ }^{\mathbf{b}}$ The equations were reported earlier in Morgan et al. [18]; ${ }^{\mathbf{c}} \mathrm{C}_{\mathrm{away}}$ was calculated by using the median indoor air concentration of $\mathrm{C}_{\mathrm{hi}}$ and $\mathrm{C}_{\mathrm{di}}$ since air samples were not collected in locations where children spent their time away from home or daycare. 
The estimated potential exposures (ng/day) of the $129 \mathrm{NC}$ children were calculated for "frequently detected" pesticides through the dietary, nondietary, and inhalation routes using equations reported in a previous article [18] and are presented in Table 2. A "frequently detected" pesticide was defined here as having at least a 50\% detection frequency in two or more different sampled media. There were a total of eight pesticides that met this criteria: $\alpha$-chlordane, $\gamma$-chlordane, heptachlor, chlorpyrifos, diazinon, cis-permethrin, trans-permethrin, and 2,4-D. In Table 2, the children's potential intake doses (ng/kg/day) to the frequently detected pesticides were computed by dividing $\mathrm{E}_{\text {dietary, }}$ $\mathrm{E}_{\text {nondietary, }}$ or $\mathrm{E}_{\text {inhalation }}$ by their body weight $(\mathrm{kg})$ and by a default absorption rate of $50 \%$. We assumed a default $50 \%$ absorption rate for a pesticide by each route of exposure as little published data exist in humans $[23,24]$. The dermal route for the pesticides was not quantified for these children as past research has indicated that this is a minor exposure route $[14,18,19]$. In addition, the children's estimated potential aggregate exposures and potential aggregate intake doses were calculated for frequently detected pesticides (chlorpyrifos, permethrin, and 2,4-D) that had measureable levels for all three exposure routes. All statistical analyses were performed using SAS Version 8.0 (SAS, Cary, NC, USA).

\section{Results}

\subsection{Demographic and Pesticide-use Data}

In this NC cohort of CTEPP preschool children, there were a total of 58 males and 71 females. The children's median age was 47 months, and their ages ranged between 20 months and 66 months. The racial background of the children was reported as white $(55 \%)$, black (37\%), Hispanic (4\%), other $(3 \%)$, and unknown (1\%). The majority of the children $(61 \%)$ lived in homes with a total household income of less than $\$ 50,000$ per year. The children's median body weight was $16.7 \mathrm{~kg}$, and ranged from 10.4 to $44.1 \mathrm{~kg}$.

In the questionnaires, $74 \%$ and $38 \%$ of the 129 homeowners reported applying products containing insecticides and herbicides, respectively, since residing ( $\geq 1$ year) at their residences. Of these homeowners, 90\% had used products that contained insecticides and $88 \%$ had used products that contained herbicides within a year of field sampling at their homes. For the 13 daycares, $62 \%$ and $31 \%$ had applied products with insecticides and herbicides, respectively, in the past at their facilities ( $\geq 1$ year). Of these daycares, $88 \%$ had used products with insecticides and $100 \%$ had used products with herbicides within a year of the field sampling.

\subsection{Pesticide Concentrations in Environmental and Personal Media}

Tables 3 and 4 present the distributions of the 16 pesticides measured in the environmental media collected at 129 homes and 13 daycare centers in NC. The OC insecticides were detected in all sampled media, except for aldrin in soil samples and outdoor air samples (daycares, only). Among the measured OC insecticides, only $\alpha$-chlordane and $\gamma$-chlordane were detected $\geq 50 \%$ in the dust, ndoor air, and outdoor air samples at both locations. 
Table 3. Concentrations of pesticides in environmental media collected at 129 children's homes in North Carolina.

\begin{tabular}{|c|c|c|c|c|c|c|c|c|c|c|c|c|c|c|c|c|}
\hline \multirow{2}{*}{ Pesticide } & \multicolumn{4}{|c|}{ Soil (ng/g) } & \multicolumn{4}{|c|}{ Dust (ng/g) } & \multicolumn{4}{|c|}{ Outdoor Air (ng/m $\left.\mathbf{m}^{3}\right)$} & \multicolumn{4}{|c|}{ Indoor Air (ng/m $\left.\mathbf{m}^{3}\right)$} \\
\hline & $\%$ & 50th & 95th & Range & $\%$ & 50th & 95th & Range & $\%$ & 50th & 95th & Range & $\%$ & 50th & 95th & Range \\
\hline \multicolumn{17}{|c|}{ Organochlorine Insecticides } \\
\hline Aldrin & 0 & ---- & ---- & ---- & 16 & $<^{a}$ & 35.4 & $<-276$ & 9 & $<$ & 0.27 & $<-2.9$ & 38 & $<$ & 9.90 & $<-413$ \\
\hline$\alpha$-Chlordane & 30 & $<$ & 16.2 & $<-2,670$ & 95 & 22.0 & 401 & $<-2,010$ & 50 & 0.08 & 1.19 & $<-3.74$ & 98 & 0.89 & 24.6 & $<-54.7$ \\
\hline$\gamma$-Chlordane & 30 & $<$ & 11.9 & $<-4,440$ & 97 & 30.6 & 649 & $<-1,980$ & 61 & 0.12 & 1.78 & $<-10.9$ & 100 & 1.51 & 40.5 & $0.09-92.1$ \\
\hline$p, p$ '-DDT & 20 & $<$ & 13.3 & $<-544$ & 39 & $<$ & 208 & $<-4,080$ & 12 & $<$ & 0.32 & $<-2.16$ & 37 & $<$ & 3.28 & $<-90.2$ \\
\hline Dieldrin & 14 & $<$ & 9.78 & $<-321$ & 43 & $<$ & 158 & $<-473$ & 13 & $<$ & 0.40 & $<-1.6$ & 41 & $<$ & 7.47 & $<-56.3$ \\
\hline Endrin & 4 & $<$ & $<$ & $<-5.44$ & 19 & $<$ & 118 & $<-317$ & 39 & $<$ & 0.95 & $<-1.49$ & 34 & $<$ & 1.59 & $<-15.1$ \\
\hline Heptachlor & 3 & $<$ & $<$ & $<-86.5$ & 41 & $<$ & 552 & $<-1,610$ & 61 & 0.29 & 4.68 & $<-39.3$ & 92 & 6.80 & 124 & $<-465$ \\
\hline Lindane & 6 & $<$ & 0.68 & $<-60.2$ & 14 & $<$ & 51.2 & $<-1,000$ & 12 & $<$ & 0.42 & $<-6.15$ & 13 & $<$ & 7.73 & $<-18.5$ \\
\hline \multicolumn{17}{|c|}{ Organophosphorus Insecticides } \\
\hline Chlorpyrifos $^{\mathbf{b}}$ & 18 & $<$ & 16.7 & $<-1,170$ & 100 & 135 & 1,180 & $11.5-15,100$ & 84 & 0.27 & 4.3 & $<-45.9$ & 100 & 6.21 & 70.7 & $0.3-391$ \\
\hline Diazinon & 18 & $<$ & 4.24 & $<-5,470$ & 96 & 17.5 & 388 & $<-11,000$ & 50 & 0.09 & 1.10 & $<-42.8$ & 100 & 2.02 & 63.7 & $0.14-1,780$ \\
\hline \multicolumn{17}{|c|}{ Pyrethroid Insecticides } \\
\hline Cyfluthrin & 12 & $<$ & 32.1 & $<-187$ & 48 & $<$ & 1660 & $<-4,100$ & 0 & ---- & ---- & ---- & 4 & $<$ & $<$ & $<-183$ \\
\hline cis-Permethrin & 23 & $<$ & 13.4 & $<-1,360$ & 100 & 804 & 21,100 & $67.1-311,000$ & 16 & $<$ & 0.48 & $<-1.62$ & 66 & 0.58 & 7.9 & $<-34.4$ \\
\hline trans-Permethrin & 23 & $<$ & 17.9 & $<-1,610$ & 100 & 629 & 19,400 & $51.3-32,000$ & 16 & $<$ & 0.26 & $<-1.01$ & 66 & 0.36 & 7.62 & $<-40.9$ \\
\hline \multicolumn{17}{|l|}{ Acid Herbicides } \\
\hline Dicamba & 6 & $<$ & 0.40 & $<-26.1$ & 23 & $<$ & 70.7 & $<-159$ & 8 & $<$ & 0.43 & $<-0.76$ & 1 & $<$ & $<$ & $<-0.48$ \\
\hline $2,4-\mathrm{D}^{\mathrm{c}}$ & 19 & $<$ & 3.28 & $<-30.5$ & 66 & 32.3 & 820 & $<-7,390$ & 19 & $<$ & 0.76 & $<-2.26$ & 46 & $<$ & 3.03 & $<-5.88$ \\
\hline $2,4,5-\mathrm{T}$ & 1 & $<$ & $<$ & $<-1.12$ & 0 & ---- & --- & ---- & 9 & $<$ & 0.49 & $<-1.66$ & 7 & $<$ & 0.67 & $<-2.12$ \\
\hline
\end{tabular}

Notes: ${ }^{\mathbf{a}}$ Below the limit of detection (LOD) for a pesticide; ${ }^{\mathbf{b}}$ Concentration data in environmental media at 129 NC children's homes were previously reported in Morgan et al.[18]; ${ }^{\mathbf{c}}$

Concentration data in environmental media were reported for 66 out of $127 \mathrm{NC}$ children's homes in Morgan et al. [20]. 
Table 4. Concentrations of pesticides in environmental media collected at 13 child daycare centers in North Carolina.

\begin{tabular}{|c|c|c|c|c|c|c|c|c|c|c|c|c|c|c|c|c|}
\hline \multirow{2}{*}{ Pesticide } & \multicolumn{5}{|c|}{ Soil (ng/g) } & \multicolumn{3}{|c|}{ Dust (ng/g) } & \multicolumn{4}{|c|}{ Outdoor Air (ng/m $\left.\mathbf{m}^{3}\right)$} & \multicolumn{4}{|c|}{ Indoor Air (ng/m³) } \\
\hline & $\%$ & 50th & 95th & Range & $\%$ & 50th & 95th & Range & $\%$ & 50th & 95th & Range & $\%$ & 50th & 95th & Range \\
\hline \multicolumn{17}{|c|}{ Organochlorine Insecticides } \\
\hline Aldrin & 0 & ---- & ---- & ---- & 15 & $<{ }^{a}$ & 1,410 & $<-2,440$ & 0 & $<$ & ---- & ---- & 55 & 0.82 & 29.5 & $<-35.0$ \\
\hline$\alpha$-Chlordane & 46 & $<$ & 11.9 & $<-11.9$ & 100 & 43.0 & 987 & $4.61-1,080$ & 85 & 0.15 & 108 & $<-108$ & 100 & 0.51 & 15.7 & $0.14-17.7$ \\
\hline$\gamma$-Chlordane & 46 & $<$ & 13.1 & $<-13.1$ & 100 & 66.6 & 1,210 & $5.57-1,210$ & 85 & 0.28 & 115 & $<-115$ & 100 & 0.79 & 42.6 & $0.21-47.7$ \\
\hline$p, p^{\prime}$-DDT & 15 & $<$ & 7.78 & $<-7.78$ & 30 & $<$ & 426 & $<-657$ & 15 & $<$ & 0.34 & $<-0.34$ & 20 & $<$ & 3.04 & $<-5.85$ \\
\hline Dieldrin & 8 & $<$ & 2.49 & $<-2.49$ & 58 & 20.3 & 1,730 & $<-1,730$ & 23 & $<$ & 0.50 & $<-0.50$ & 30 & $<$ & 4.81 & $<-4.93$ \\
\hline Endrin & 8 & $<$ & 3.03 & $<-3.03$ & 15 & $<$ & 111 & $<-159$ & 54 & 0.17 & 1.04 & $<-1.04$ & 35 & $<$ & 1.22 & $<-1.64$ \\
\hline Heptachlor & 23 & $<$ & 2.03 & $<-2.03$ & 55 & 19.4 & 942 & $<-1,040$ & 69 & 0.54 & 54.8 & $<-54.8$ & 100 & 5.40 & 284 & $1.4-287$ \\
\hline Lindane & 8 & $<$ & 0.93 & $<-0.93$ & 20 & $<$ & 51.4 & $<-53.6$ & 8 & $<$ & 0.11 & $<-0.11$ & 20 & $<$ & 7.05 & $<-8.97$ \\
\hline \multicolumn{17}{|c|}{ Organophosphorus Insecticides } \\
\hline Chlorpyrifos $^{\mathbf{b}}$ & 7 & $<$ & $<$ & $<-0.76$ & 100 & 142 & 921 & $12.4-921$ & 77 & 0.34 & 1.53 & $<-1.53$ & 100 & 3.0 & 25.3 & $0.58-29.4$ \\
\hline Diazinon & 0 & ---- & ---- & ---- & 100 & 65.2 & 6,880 & $3.06-6,880$ & 62 & 0.12 & 0.29 & $<-0.29$ & 100 & 2.27 & 70.2 & $0.17-106$ \\
\hline \multicolumn{17}{|c|}{ Pyrethroid Insecticides } \\
\hline Cyfluthrin & 8 & $<$ & 42.2 & $<-42.2$ & 42 & $<$ & 1,750 & $<-1750$ & 0 & --- & ---- & ---- & 10 & $<$ & 1.60 & $<-1.74$ \\
\hline cis-Permethrin & 8 & $<$ & 2.55 & $<-2.55$ & 100 & 806 & 19,700 & $113-29,000$ & 39 & $<$ & 0.45 & $<-0.45$ & 55 & 0.11 & 2.45 & $<-3.05$ \\
\hline trans-Permethrin & 8 & $<$ & 2.20 & $<-2.20$ & 100 & 856 & 209,00 & $125-29,900$ & 39 & $<$ & 0.34 & $<-0.34$ & 50 & $<$ & 2.14 & $<-2.76$ \\
\hline \multicolumn{17}{|l|}{ Acid Herbicides } \\
\hline Dicamba & 0 & ---- & ---- & ---- & 5 & $<$ & $<$ & $<-23.6$ & 8 & $<$ & 0.21 & $<-0.21$ & 0 & ---- & ---- & ---- \\
\hline $2,4-\mathrm{D}$ & 0 & ---- & ---- & ---- & 75 & 23.0 & 77.5 & $<-93.7$ & 46 & $<$ & 0.66 & $<-0.66$ & 60 & 0.33 & 6.17 & $<-6.50$ \\
\hline $2,4,5-\mathrm{T}$ & 0 & ---- & ---- & ---- & 5 & $<$ & $<$ & $<-23.6$ & 8 & $<$ & 2.21 & $<-2.21$ & 5 & $<$ & $<$ & $<-0.63$ \\
\hline
\end{tabular}

Notes: ${ }^{\mathbf{a}}$ Below the limit of detection (LOD) for a pesticide; ${ }^{\mathbf{b}}$ Concentration data in environmental media at 13 child care centers were previously reported in Morgan et al. [18]. 
In addition, heptachlor was detected $>50 \%$ in the outdoor air and indoor air samples at both the homes and daycare centers. The OP insecticides, chlorpyrifos and diazinon, were detected $\geq 50 \%$ in the dust, outdoor air, and indoor air samples at both settings. In particular at the homes, the median levels of chlorpyrifos were at least three times greater than the median levels of diazinon in the dust, outdoor air, and indoor air samples. For the PY insecticides, cis-permethrin and trans-permethrin were both detected $\geq 50 \%$ in the dust and indoor air samples at both locations. Cyfluthrin was detected $>40 \%$ in only the dust samples in both settings. 2,4-D was the only AC herbicide that was detected $>50 \%$ in the dust samples in both settings. Of the measured pesticides in the environmental media, the combined isomers of chlordane had the highest 95th percentile concentrations ( $\geq 25.0 \mathrm{ng} / \mathrm{g}$ ) in soil samples at both the homes and daycare centers. For the dust samples, the median levels of the combined isomers of permethrin $(>1,400 \mathrm{ng} / \mathrm{g})$ were at least 10 times greater than the median levels for all of the other measured pesticides at both locations. Heptachlor had the highest median concentrations occurring among these pesticides in the indoor air samples $\left(\geq 5.40 \mathrm{ng} / \mathrm{m}^{3}\right)$ in both settings.

Tables 5 and 6 provide the distributions of the 16 pesticides measured in the personal media at 129 homes and 13 daycare centers in NC. For the hand wipe samples, $\alpha$-chlordane, $\gamma$-chlordane, chlorpyrifos, cis-permethrin, and trans-permethrin were detected above $>50 \%$ in both settings. However, the median levels of cis/trans-permethrin were at least five times greater in the hand wipe samples than for all of the other measured pesticides. Chlorpyrifos and 2,4-D were detected above $50 \%$ in the solid food samples at the homes, and only chlorpyrifos was detected $>50 \%$ in the solid food samples at the daycares. Lastly, none of the pesticides were detected often $(<19 \%)$ in the liquid food samples in either setting.

\subsection{Estimated Potential Exposures and Potential Intake Doses to Pesticides by Route}

The children's estimated median potential exposures (ng/day) and potential intake doses (ng/kg/day) to the eight frequently detected pesticides through the dietary ingestion, nondietary ingestion, and inhalation routes are presented in Table 7. Also for comparison in Table 7, we have provided the established oral reference doses (RfD's) and/or inhalation reference concentrations (RfC's) for these pesticides that are available in the US EPA's Integrated Risk Management System (IRIS) [25]. The estimated median potential intake doses of the children through the dietary ingestion route were the highest for the combined isomers of permethrin at $4.84 \mathrm{ng} / \mathrm{kg} / \mathrm{day}$ and for $2,4-\mathrm{D}$ also at $4.84 \mathrm{ng} / \mathrm{kg} / \mathrm{day}$. For the nondietary ingestion route, the children had the highest median potential intake dose of $2.39 \mathrm{ng} / \mathrm{kg} /$ day to the combined isomers of permethrin which was at least an order of magnitude higher than for the next highest pesticide, chlorpyrifos $(0.156 \mathrm{ng} / \mathrm{kg} / \mathrm{day})$. In contrast, the children's estimated median potential intake dose through the inhalation route was the most to heptachlor at $1.71 \mathrm{ng} / \mathrm{kg} / \mathrm{day}$, followed by chlorpyrifos at $1.42 \mathrm{ng} / \mathrm{kg} / \mathrm{day}$. 
Table 5. Concentrations of pesticides in personal exposure samples collected from 129 children at their homes in North Carolina.

\begin{tabular}{|c|c|c|c|c|c|c|c|c|c|c|c|c|}
\hline \multirow{2}{*}{ Pesticide } & \multicolumn{4}{|c|}{ Hand Wipe (ng/cm²) } & \multicolumn{4}{|c|}{ Solid Food (ng/g) } & \multicolumn{4}{|c|}{ Liquid Food (ng/mL) } \\
\hline & $\%$ & 50th & 95th & Range & $\%$ & 50th & 95th & Range & $\%$ & 50th & 95th & Range \\
\hline \multicolumn{13}{|c|}{ Organochlorine Insecticides } \\
\hline Aldrin & 1 & $<^{a}$ & $<$ & $<-0.02$ & 2 & $<$ & $<$ & $<-0.47$ & 0 & ---- & ---- & ---- \\
\hline$\alpha$-Chlordane & 51 & 0.004 & 0.06 & $<-0.16$ & 17 & $<$ & 0.15 & $<-0.47$ & 5 & $<$ & $<$ & $<-0.04$ \\
\hline$\gamma$-Chlordane & 54 & 0.01 & 0.09 & $<-0.17$ & 19 & $<$ & 0.22 & $<-0.47$ & 0 & ---- & ---- & ---- \\
\hline$p, p^{\prime}-\mathrm{DDT}$ & 8 & $<$ & 0.07 & $<-0.74$ & 4 & $<$ & $<$ & $<-2.52$ & 2 & $<$ & $<$ & $<-0.10$ \\
\hline Dieldrin & 4 & $<$ & $<$ & $<-0.21$ & 2 & $<$ & $<$ & $<-1.58$ & 0 & ---- & ---- & ---- \\
\hline Endrin & 3 & $<$ & $<$ & $<-0.12$ & 1 & $<$ & $<$ & $<-0.47$ & 0 & ---- & ---- & ---- \\
\hline Heptachlor & 22 & $<$ & 0.04 & $<-0.15$ & 14 & $<$ & 0.73 & $<-1.53$ & 0 & ---- & ---- & ---- \\
\hline Lindane & 2 & $<$ & $<$ & $<-0.01$ & 8 & $<$ & 0.84 & $<-12.4$ & 2 & $<$ & $<$ & $<-0.20$ \\
\hline \multicolumn{13}{|c|}{ Organophosphorus Insecticides } \\
\hline Chlorpyrifos ${ }^{\mathbf{b}}$ & 80 & 0.02 & 0.28 & $<-0.74$ & 65 & 0.19 & 2.09 & $<-19.7$ & 10 & $<$ & 0.06 & $<-1.71$ \\
\hline Diazinon & 46 & $<$ & 0.08 & $<-1.55$ & 22 & $<$ & 0.41 & $<-6.73$ & 1 & $<$ & $<$ & $<-0.21$ \\
\hline \multicolumn{13}{|c|}{ Pyrethroids Insecticides } \\
\hline Cyfluthrin & 32 & $<$ & 0.44 & $<-0.95$ & 6 & $<$ & 0.90 & $<-4.65$ & 0 & ---- & ---- & ---- \\
\hline cis-Permethrin & 87 & 0.06 & 1.46 & $<-64.0$ & 46 & $<$ & 15.6 & $<-80.7$ & 18 & $<$ & 0.33 & $<-1.02$ \\
\hline trans-Permethrin & 87 & 0.05 & 1.27 & $<-66.7$ & 46 & $<$ & 8.7 & $<-70.4$ & 17 & $<$ & 0.16 & $<-0.84$ \\
\hline \multicolumn{13}{|l|}{ Acid Herbicides } \\
\hline Dicamba & 0 & ---- & ---- & ---- & 16 & $<$ & 0.88 & $<-1.67$ & 0 & ---- & ---- & ---- \\
\hline $2,4-D^{c}$ & 9 & $<$ & 0.02 & $<-0.04$ & 56 & 0.35 & 2.12 & $<-4.36$ & 2 & $<$ & $<$ & $<-0.60$ \\
\hline $2,4,5-\mathrm{T}$ & 0 & ---- & ---- & ---- & 2 & $<$ & $<$ & $<-1.47$ & 0 & ---- & ---- & ---- \\
\hline
\end{tabular}


Table 6. Concentrations of pesticides in personal exposure samples collected from 63 children at their daycare centers in North Carolina.

\begin{tabular}{|c|c|c|c|c|c|c|c|c|c|c|c|c|}
\hline \multirow{2}{*}{ Pesticide } & \multicolumn{4}{|c|}{ Hand Wipe $\left(\mathrm{ng} / \mathrm{cm}^{2}\right)$} & \multicolumn{4}{|c|}{ Solid Food (ng/g) } & \multicolumn{4}{|c|}{ Liquid Food (ng/mL) } \\
\hline & $\%$ & 50th & 95th & Range & $\%$ & 50th & 95th & Range & $\%$ & 50th & 95th & Range \\
\hline \multicolumn{13}{|c|}{ Organochlorine Insecticides } \\
\hline Aldrin & 3 & $<^{a}$ & $<$ & $<-0.17$ & 4 & $<$ & $<$ & $<-0.17$ & 0 & ---- & ---- & ---- \\
\hline$\alpha$-Chlordane & 65 & 0.01 & 0.03 & $<-0.07$ & 13 & $<$ & 0.11 & $<-0.33$ & 9 & $<$ & 0.04 & $<-0.04$ \\
\hline$\gamma$-Chlordane & 65 & 0.01 & 0.05 & $<-0.08$ & 13 & $<$ & 0.15 & $<-0.34$ & 0 & ---- & ---- & ---- \\
\hline$p, p^{\prime}-\mathrm{DDT}$ & 3 & $<$ & $<$ & $<-0.46$ & 4 & $<$ & $<$ & $<-1.31$ & 0 & ---- & ---- & ---- \\
\hline Dieldrin & 3 & $<$ & $<$ & $<-0.22$ & 0 & ---- & ---- & ---- & 0 & ---- & ---- & ---- \\
\hline Endrin & 3 & $<$ & $<$ & $<-0.04$ & 0 & ---- & ---- & ---- & 0 & ---- & ---- & ---- \\
\hline Heptachlor & 23 & $<$ & 0.05 & $<-0.05$ & 13 & $<$ & 0.51 & $<-0.69$ & 0 & ---- & ---- & ---- \\
\hline Lindane & 0 & ---- & ---- & ---- & 4 & $<$ & $<$ & $<-0.52$ & 0 & ---- & ---- & ---- \\
\hline \multicolumn{13}{|c|}{ Organophosphorus Insecticides } \\
\hline Chlorpyrifos ${ }^{\mathbf{b}}$ & 68 & 0.02 & 0.07 & $<-0.08$ & 54 & 0.10 & 0.85 & $<-0.95$ & 14 & $<$ & 0.06 & $<-0.15$ \\
\hline Diazinon & 58 & 0.01 & 0.05 & $<-0.17$ & 25 & $<$ & 0.17 & $<-0.89$ & 0 & ---- & ---- & ---- \\
\hline \multicolumn{13}{|c|}{ Pyrethroids Insecticides } \\
\hline Cyfluthrin & 19 & $<$ & 0.33 & $<-0.63$ & 4 & $<$ & $<$ & $<-5.31$ & 0 & ---- & ---- & ---- \\
\hline cis-Permethrin & 94 & 0.07 & 0.31 & $<-2.19$ & 25 & $<$ & 5.17 & $<-218$ & 14 & $<$ & 0.06 & $<-0.55$ \\
\hline trans-Permethrin & 94 & 0.04 & 0.26 & $<-2.13$ & 25 & $<$ & 2.96 & $<-149$ & 14 & $<$ & 0.05 & $<-0.66$ \\
\hline \multicolumn{13}{|l|}{ Acid Herbicides } \\
\hline Dicamba & 0 & ---- & ---- & ---- & 4 & $<$ & $<$ & $<-0.33$ & 0 & ---- & ---- & ---- \\
\hline $2,4-\mathrm{D}$ & 3 & $<$ & $<$ & $<-0.02$ & 38 & $<$ & 1.55 & $<-2.17$ & 0 & ---- & ---- & ---- \\
\hline $2,4,5-\mathrm{T}$ & 0 & ---- & ---- & ---- & 0 & ---- & ---- & ---- & 0 & ---- & ---- & ---- \\
\hline
\end{tabular}

Notes: ${ }^{\mathbf{a}}$ Below the limit of detection (LOD) for a pesticide; ${ }^{\mathbf{b}}$ Concentration data in media at 13 child care centers were previously reported in Morgan et al. [18]. 
Table 7. The preschool children's estimated median potential exposures and potential intake doses to frequently detected pesticides by exposure route ${ }^{\text {a }}$.

\begin{tabular}{|c|c|c|c|c|c|c|c|c|c|}
\hline \multirow{2}{*}{ Pesticide Class $^{b}$} & \multirow{2}{*}{ Pesticide } & \multicolumn{3}{|c|}{ Potential Exposure (ng/day) } & \multicolumn{3}{|c|}{ Potential Intake Dose $^{\mathrm{c}}(\mathrm{ng} / \mathrm{kg} /$ day $)$} & \multirow{2}{*}{$\begin{array}{c}\text { Oral RfD } \\
\text { (ng/kg/day) }\end{array}$} & \multirow{2}{*}{$\begin{array}{c}\text { Inhalation RfC } \\
\left(\mathbf{n g} / \mathbf{m}^{3} / \text { day }\right)\end{array}$} \\
\hline & & Dietary & Nondietary & Inhalation & Dietary & Nondietary & Inhalation & & \\
\hline $\mathrm{OC}$ & $\gamma$-Chlordane & $<$ & 2.69 & 12.7 & $<$ & 0.083 & 0.422 & $500^{\mathrm{e}}$ & $700^{e}$ \\
\hline OP & Chlorpyrifos $^{\mathbf{d}}$ & 81.1 & 5.16 & 47.2 & 2.5 & 0.156 & 1.42 & ---- & ---- \\
\hline OP & Diazinon & $<$ & 0.984 & 16.9 & $<$ & 0.03 & 0.507 & ---- & ---- \\
\hline PY & cis-Permethrin & 84.7 & 48.1 & 4.64 & 2.63 & 1.39 & 0.137 & $50,000^{\mathrm{e}}$ & --- \\
\hline
\end{tabular}

Notes: ${ }^{\text {a }}$ Estimated for pesticides that had $\geq 45 \%$ detects in two or more sampled media; ${ }^{\mathbf{b}}$ Pesticide classes include organochlorine insecticides (OC), organophosphorus insecticides (OP), pyrethroid insecticides (PY), and AC herbicides; ${ }^{\mathbf{c}}$ Assuming a $50 \%$ absorption for a pesticide for each route of exposure; ${ }^{\mathrm{d}}$ Data were calculated from Morgan et al. [18]; ${ }^{\mathbf{e}}$ Value equals total chlordane or total permethrin (not individual isomers); ${ }^{\mathbf{f}}$ No oral reference dose (RfD) or inhalation reference concentration (RfC) was available in the US EPA's Integrated Risk Information System (IRIS) [25]. 


\subsection{Estimated Potential Aggregate Exposures and Potential Aggregate Intake Doses to Pesticides}

The children's estimated potential aggregate intake doses by all three exposure routes were quantifiable for chlorpyrifos, cis/trans-permethrin, and 2,4-D and are depicted as a box-and-whiskers plot in Figure 1. The estimated median potential aggregate intake doses of the children were $4.6 \mathrm{ng} / \mathrm{kg} / \mathrm{day}$ for chlorpyrifos, $12.5 \mathrm{ng} / \mathrm{kg} /$ day for cis/trans-permethrin, and $4.9 \mathrm{ng} / \mathrm{kg} /$ day for 2,4-D. At the 95th percentile, the children's estimated potential aggregate intake doses were $31.7 \mathrm{ng} / \mathrm{kg} / \mathrm{day}$ (chlorpyrifos), $397 \mathrm{ng} / \mathrm{kg} /$ day (cis/trans-permethrin), and $22.5 \mathrm{ng} / \mathrm{kg} / \mathrm{day}(2,4-\mathrm{D})$. The results show that dietary ingestion $(>60 \%)$ was the predominant route of the children's exposures to all three pesticides.

Figure 1. The children's estimated potential aggregate intake doses to chlorpyrifos, permethrin, and 2,4-D ${ }^{\text {a,b }}$.

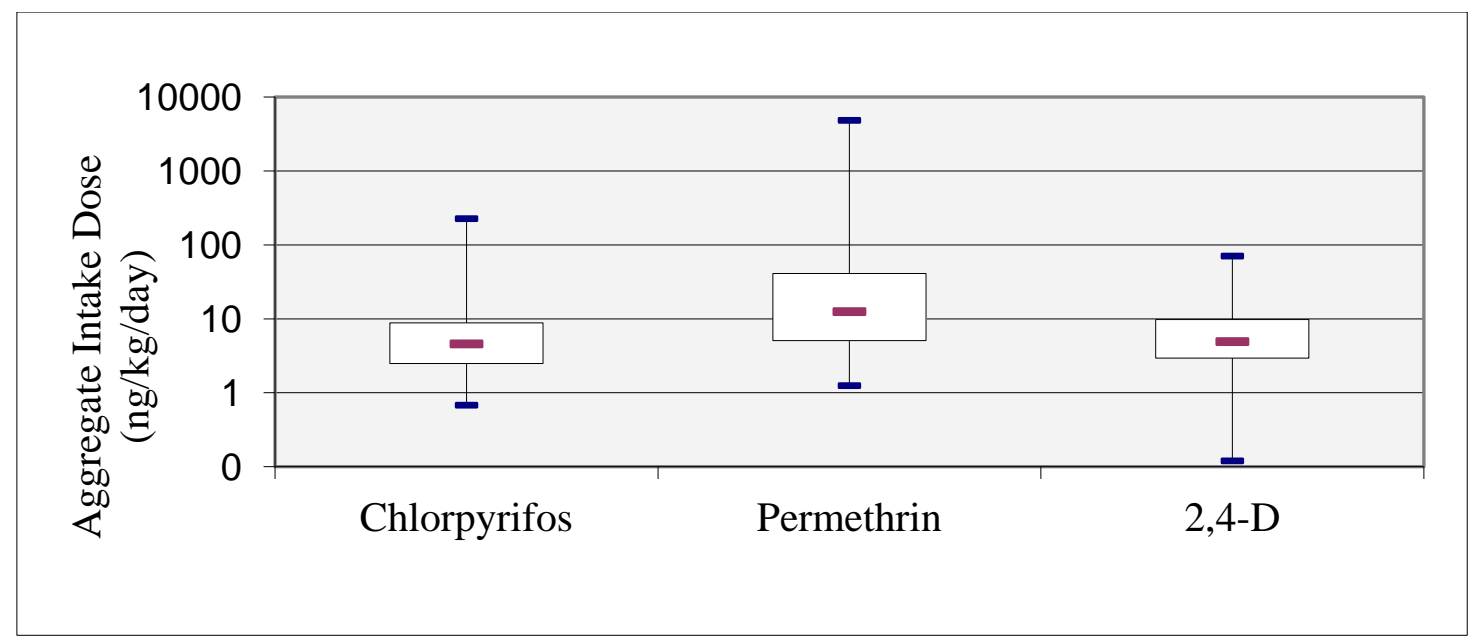

Notes: ${ }^{\mathbf{a}}$ Combined cis- and trans-isomers; ${ }^{\mathbf{b}}$ The line within each box represent the median concentration value for a pesticide.

\section{Discussion}

As limited published data exist on the absorption rates of many pesticides in humans, scientists must frequently rely on default assumption values to help calculate the estimated potential intake doses of children to pesticides by exposure route. A common approach is to use the most conservative absorption rate value of $100 \%$ for a pesticide for a child by exposure route (inhalation and ingestion) [15,26,27]. This approach assumes that $100 \%$ of the total amount of the pesticide, after exposure, is absorbed into the body [26]. However in recent years, research has shown that pesticide absorption rates in humans can vary greatly by such things as class of pesticide, exposure route, and administered vehicle (e.g., corn oil), and these absorption rates have been generally substantially less than $100 \%$ [28-31]. Therefore in the CTEPP study, we selected a more reasonable default absorption rate of $50 \%$ for a pesticide by each exposure route [24]. Appendix Table A1 illustrates the differences in the maximum potential intake doses for the CTEPP children by route when using the default absorption rate of $100 \%$ versus $50 \%$. For example, the maximum potential dietary intake dose of one CTEPP child to permethrin is twice the amount when using a $100 \%$ absorption rate $(9,700 \mathrm{ng} / \mathrm{kg} /$ day $)$ compared to using our $50 \%$ absorption rate $(4,850$ 
$\mathrm{ng} / \mathrm{kg} /$ day). More research is needed to quantify the actual absorption rates of pesticides by route in humans (e.g., in vitro assays) which would greatly improve pesticide exposure assessments for children.

In this current work, the results show that of the measured OC insecticides only $\alpha$-chlordane, $\gamma$-chlordane, and heptachlor were detected $\geq 50 \%$ in several different media at the preschool children's homes and daycare centers in NC. Inhalation of indoor air and outdoor air was found to be the predominant exposure route of the children to both $\alpha / \gamma$-chlordane $(\sim 83 \%)$ and heptachlor ( 98\%). An interesting observation was that the NC CTEPP preschool children had the highest estimated median potential inhalation dose of $1.71 \mathrm{ng} / \mathrm{kg} /$ day to heptachlor (maximum value $=118 \mathrm{ng} / \mathrm{kg} / \mathrm{day}$ ) compared to all of the other pesticides measured in this study. This finding is supported by research conducted by Wilson et al. [14,15] showing that inhalation was a major exposure route of nine preschool children to eight different OC insecticides at their homes and daycare centers in NC in 1997, and heptachlor substantially contributed to their OC insecticide exposure by this route. This is a concern as almost all uses of heptachlor were phased-out by the late 1980's, except to control fire ants in subsurface electrical power transformers and cable boxes, because of its persistence in the environment and in the body [1]. In addition, an established RfC for heptachlor is currently not available in the U.S. EPA's IRIS [25], therefore, we could not ascertain if the children's potential inhalation doses were below a level of concern in these environments. Because heptachlor is persistent and bioaccumulative in the body, more research is needed to understand children's temporal exposures to heptachlor and potential health risks in places where children frequently spend their time (i.e., residences, daycares, schools, and parks) [1].

At the time that the CTEPP study was conducted in 2000-2001, the OP insecticides, chlorpyrifos and diazinon, and the PY insecticides, permethrin and cyfluthrin, were commonly used to control insect pests at dwellings and on agricultural crops. Our results show that these insecticides, except for cyfluthrin, were detected $\geq 50 \%$ in several different media at the children's homes and daycare centers. Of these insecticides, the CTEPP children had the highest estimated median potential aggregate intake doses to the combined isomers of permethrin $(12.5 \mathrm{ng} / \mathrm{kg} /$ day $)$, followed by chlorpyrifos (4.6 ng/kg/day). Dietary ingestion was the predominant route of the children's exposures to both permethrin $(\sim 65 \%)$ and chlorpyrifos $(\sim 61 \%)$. In comparison, Morgan et al. $[19,23]$ have reported about three times lower estimated median potential aggregate intake dose $(4.0 \mathrm{ng} / \mathrm{kg} / \mathrm{day})$ to the combined isomers of permethrin for 111 preschool children from the $\mathrm{OH}$ component of the CTEPP study; dietary ingestion $(\sim 60 \%)$ also contributed the most to their exposure. In another study conducted in 2001 by Tulve et al. [32,33], they showed that permethrin was frequently detected $(>50 \%)$ in several media at nine preschool children's homes in Florida that reported frequently using products containing pesticides. The authors reported that both dermal (57\%) and dietary ingestion (33\%) likely contributed substantially to the children's cumulative exposures (nmol/day; not intake dose) to pyrethroids (which included permethrin), however, they state that the results are limited due to the small sample size of children [33]. These above studies suggest that there are likely geographic differences in the use and amount of permethrin applied in residential settings in the U.S. and more research is needed. For chlorpyrifos, our results $(4.6 \mathrm{ng} / \mathrm{kg} /$ day) were about six times lower than the results reported in Wilson et al. [15] having estimated median potential aggregate exposures of $30.0 \mathrm{ng} / \mathrm{kg} / \mathrm{day}$ for nine preschool children at their homes and daycare centers in NC in 1997. In contrast, our study results are only about two times lower than the results reported in Clayton et al. [34] 
showing a median aggregate intake dose to chlorpyrifos of $11.7 \mathrm{ng} / \mathrm{kg} / \mathrm{day}$ for 56 children, ages 3-12 years old, at their homes in Minnesota in 1997. In the more recent Pesticide Exposures of Preschool Children Over Time (PEPCOT) study conducted between 2003-2005 [27], the authors reported estimated median potential aggregate intake doses of 8.0, 6.2, and $6.2 \mathrm{ng} / \mathrm{kg} / \mathrm{day}$ to chlorpyrifos (assuming a 100\% absorption rate) for 50 preschool children (older sibling) at their homes in NC in 2003, 2004, and 2005, respectively. The CTEPP children's estimated median potential aggregate intake doses to chlorpyrifos are slightly higher than for the PEPCOT children when assuming a $100 \%$ default absorption rate for a pesticide. Overall, these above studies suggest that preschool children's exposures to chlorpyrifos are declining over the last decade in the U.S. and are likely associated with the U.S. EPA's 2001 phase-out of this insecticide [7,27]. This information is supported by Clune et al. [35] that showed a substantial decline in the last decade in urinary dialkylphosphate (DAP) levels of OP insecticides in over 3,000 adults from the U.S. National Health and Nutrition Examination Survey (NHANES III [1988-1994] and NHANES 1999-2004). The authors suggest that the lower DAP levels appear to be related to the U.S. EPA phase-out of chlorpyrifos and diazinon at residences and similar settings [35].

Among the measured AC herbicides in our study, only 2,4-D was detected above 50\% in any medium at the children's homes and daycare centers. The CTEPP children's estimated median potential aggregate intake dose to 2,4-D was $4.9 \mathrm{ng} / \mathrm{kg} / \mathrm{day}$, and dietary ingestion accounted for almost all ( $\sim 97 \%)$ of their exposure. The children's estimated maximum potential aggregate intake dose of $70.8 \mathrm{ng} / \mathrm{kg} /$ day (data not shown) was at least 140 times lower than the RfD of 10,000 ng/kg/day in the U.S. EPA's IRIS [25]. Wilson et al. [15] reported a much higher estimated median potential aggregate intake dose of $87.6 \mathrm{ng} / \mathrm{kg} / \mathrm{day}$ to 2,4-D for nine preschool children at their homes and daycare centers in 1997. In a different study, Nishioka et al. [36] reported that dietary ingestion (94\%) was also the predominant route of young children's exposures to 2,4-D before application of this insecticide at seven Midwestern homes. However after application of 2,4-D, dietary ingestion (53\%) and nondietary (41\%) ingestion both became important routes of the children's exposures to this insecticide at home [36]. For the more recent PEPCOT study [27], the children's estimated potential median aggregate intake doses to 2,4-D ranged from 8.2-13.49 ng/kg/day between 2003-2005, and dietary ingestion (88\%) was the predominant exposure route. The above studies suggest that dietary ingestion was the predominant route of these preschool children exposures to 2,4-D between 1997 and 2005 in NC. However, it remains unclear which consumed foods likely contributed to the CTEPP children's dietary exposures to 2,4-D as solid and liquid food samples were separately consolidated over a 48-h monitoring period. Furthermore in a recent article by Morgan and Jones [37], the authors did not find any association between the reported weekly intake frequency of 65 different food items and mean urinary 2,4-D concentrations in $135 \mathrm{CTEPP}$ children from $\mathrm{NC}$ and $\mathrm{OH}$. More research is needed to quantify the levels of 2,4-D and other pesticides in individual food items consumed by young children as few data exist in the literature.

\section{Conclusions}

In conclusion, the CTEPP preschool children were concurrently exposed at low levels to a number of past-use and current-use pesticides from several sources and routes of exposure at their homes and 
daycare centers in NC. Pesticides that were detected $\geq 50 \%$ in several different media at these locations included $\alpha$-chlordane, $\gamma$-chlordane, heptachlor, chlorpyrifos, diazinon, cis-permethrin, trans-permethrin, and 2,4-D. However, the children's exposures to these eight pesticides varied greatly by exposure route. Inhalation was the predominant route of the children's exposure to $\alpha / \gamma$ chlordane $(\sim 83 \%)$, heptachlor ( $98 \%)$, and diazinon $(\sim 94 \%)$ and to a lesser extent to chlorpyrifos ( 35\%). Dietary ingestion was the major exposure route of the children to chlorpyrifos ( $\sim 61 \%)$, cis/trans-permethrin ( 65\%), and 2,4-D ( 97\%). Lastly, nondietary ingestion was also an important secondary exposure route to cis/trans-permethrin $(\sim 32 \%)$.

\section{Acknowledgments}

We would like to thank the children, their parents, and the daycare teachers for participating in this study which has generated a wealth of data on young children's exposures to pesticides in their everyday environments. We would also like to especially thank Linda Sheldon for her valuable scientific insights and technical contributions to this paper. Disclaimer: The United States Environmental Protection Agency through its Office of Research and Development funded and managed the research described here under Contract \#68-D-99-011 to Battelle. It has been subjected to agency review and approved for publication.

\section{Author Contributions}

Nancy Wilson and Jane Chuang designed the CTEPP study. Marsha Morgan was the US EPA principle investigator of the CTEPP study, and Jane Chuang was the lead contracting officer from Battelle who oversaw all of the study-related activities for the CTEPP study. Nancy Wilson provided significant technical assistance during this study. Marsha Morgan wrote the manuscript with significant technical input from Nancy Wilson and Jane Chuang.

\section{Conflicts of Interest}

The authors declare no conflict of interest.

\section{References}

1. US EPA (US Environmental Protection Agency), 1992. R.E.D. Facts: Heptachlor. Available online: http://www.epa.gov/opp00001/chem_search/reg_actions/reregistration/fs_PC -044801_1-Mar-92.pdf (accessed on 27 August 2013).

2. US EPA (US Environmental Protection Agency), 2006a. Lindane Voluntary Cancellation and RED Addendum Fact Sheet. Available online: http://www.epa.gov/oppsrrd1/REDs/factsheets/ lindane-fs_addendum.htm (accessed on 27 August 2013).

3. US EPA (US Environmental Protection Agency), 2011a. Persistent Bioaccumulative and Toxic (PBT) Chemical Program: Aldrin/Diedrin. Available online: http://www.epa.gov/pbt/ pubs/aldrin.htm (accessed on 26 August 2013). 
4. US EPA (US Environmental Protection Agency), 2011b. Persistent Bioaccumulative and Toxic (PBT) Chemical Program: Chlordane. Available online: http://www.epa.gov/pbt/pubs/ chlordane.htm (accessed on 26 August 2013).

5. US EPA (US Environmental Protection Agency). 2011c. Persistent Bioaccumulative and Toxic (PBT) Chemical Program: DDT. Available online: http://www.epa.gov/pbt/pubs/ddt.htm (accessed on 26 August 2013).

6. US EPA (US Environmental Protection Agency), 2012. Basic Information about Endrin in Drinking Water. Available online: http://water.epa.gov/drink/contaminants/basicinformation/ endrin.cfm (accessed on 27 August 2013).

7. US EPA (US Environmental Protection Agency), 2006b. Reregistration Eligibility Decision for Chlorpyrifos. Available online: http://www.epa.gov/oppsrrd1/REDs/chlorpyrifos_red.pdf (accessed on 27 August 2013).

8. US EPA (US Environmental Protection Agency), 2006c. Reregistration Eligibility Decision for Diazinon. Available online: http://www.epa.gov/oppsrrd1/REDs/diazinon_red.pdf (accessed on 27 August 2013).

9. US EPA (US Environmental Protection Agency), 2013. Pyrethrins and Pyrethroids. Available online: http://www.epa.gov/oppsrrd1/reevaluation/pyrethroids-pyrethrins.html (accessed on 12 September 2013).

10. Kerr, R.A. News and comment: EPA halts most use of herbicide 2,4,5-T. Science 1979, 203, 1090-1091.

11. Stellman, J.M.; Stellman, S.D.; Christians R.; Weber, T.; Tomasallo, C. The extent and patterns of usage of Agent Orange and other herbicides in Vietnam. Nature 2003, 422, 681-687.

12. US EPA (US Environmental Protection Agency), 2005. Reregistration eligibility decision for 2,4-D. Available online: http://www.epa.gov/oppsrrd1/REDs/24d_red.pdf (accessed on 27 August 2013).

13. US EPA (US Environmental Protection Agency), 2006. Reregistration Eligibility Decision for Dicamba and Associated Salts. Available online: http://www.epa.gov/oppsrrd1/REDs/ dicamba_red.pdf (accessed on 1 September 2013).

14. Wilson, N.K.; Chuang, J.C.; Lyu, C. Levels of persistent organic pollutants in several child care centers. J. Expo. Sci. Environ. Epidemiol. 2001, 11, 449-458.

15. Wilson, N.K.; Chuang, J.C.; Lyu, C.; Menton, R.; Morgan, M.K. Aggregate exposures of nine preschool children to persistent organic pollutants at day care and at home. J. Expo. Sci. Environ. Epidemiol. 2003, 13, 187-202.

16. U.S. EPA. Agrichemicals Food Quality Protection Act-Children and Consumers. Available online: http://www.epa.gov/agriculture/factsheets/epa-305-f-00-005.pdf (accessed on 12 September 2013).

17. Wilson, N.K.; Chuang, J.C.; Iachan, R.; Lyu, C.; Gordon, S.; Morgan, M.K.; Ozkaynak, H.; Sheldon, L.S. Design and sampling methodology for a large study of preschool children's aggregate exposures to persistent organic pollutants in their everyday environments. J. Expo. Sci. Environ. Epidemiol. 2004, 14, 260-274. 
18. Morgan, M.K.; Sheldon, L.S.; Croghan, C.W.; Jones, P.A.; Robertson, G.; Chuang, J.C.; Wilson, N.K.; Lyu, C. Exposures of preschool children to chlorpyrifos and its degradation product 3,5,6-trichloro-2-pyridinol in their everyday environments. J. Expo. Sci. Environ. Epidemiol. 2005, 15, 297-309.

19. Morgan, M.K.; Sheldon, L.S.; Croghan, C.W.; Jones, P.A.; Chuang, J.C.; Wilson, N.K. An observational study of 127 preschool children at their homes and daycare centers in Ohio: Environmental pathways to cis- and trans-permethrin exposure. Environ. Res. 2007, 104, 266-274.

20. Morgan, M.K; Sheldon, L.S.; Thomas, K.W.; Egeghy, P.P.; Croghan, C.W.; Jones, P.A.; Chuang, J.C.; Wilson, N.K. Adult and children's exposure to 2,4-D from multiple sources and pathways. J. Expo. Sci. Environ. Epidemiol. 2008, 18, 486-494.

21. Morgan, M.K.; Sheldon, L.S.; Croghan, C.W.; Jones, P.A.; Chuang, J.C.; Wilson, N.K. The reliability of using urinary biomarkers to estimate children's exposures to chlorpyrifos and diazinon. J. Expo. Sci. Environ. Epidemiol. 2011, 21, 280-290.

22. U.S. Government Printing Office, Electronic Code of Federal Regulations. Available online: http://www.ecfr.gov (accessed 31 March 2014).

23. Morgan, M.K.; Sheldon, L.S.; Croghan, C.W.; Chuang, J.C.; Lordo, R.; Wilson, N.K.; Lyu, C.; Brinkman, M.; Morse, N.; Chou, Y.; et al. A Pilot Study of Children's Total Exposure to Persistent Pesticides and Other Persistent Organic Pollutants (CTEPP); U.S. Environmental Protection Agency: Washington, DC, USA, 2005.

24. Ross, J.R.; Driver, J.H.; Cochrans, R.C.; Thonginthusak, T.; Krieger, R.I. Could pesticide toxicology studies be more relevant to occupational risk assessment. Ann. Occup. Hyg. 2001, 45, S5-S17.

25. US EPA (US Environmental Protection Agency). Integrated Risk Management System (IRIS). Available online: http://www.epa.gov/iris (accessed on 6 January 2014).

26. Lioy, P.J. Assessing total human exposure to contaminants: A multidisciplinary approach. Environ. Sci. Technol. 1990, 24, 938-945.

27. Wilson, N.K.; Strauss, W.J.; Iroz-Elardo, N.; Chuang, J.C. Exposures of preschool children to chlorpyrifos, diazinon, and pentachlorophenol, and 2,4-dichlorophenoxyacetic acid over 3 years from 2003-2005: A longitudinal model. J. Expo. Sci. Environ. Epidemiol. 2010, 20, 546-558.

28. Sauerhoff, M.; Braun, W.; Blau, G.; Gehring, P. The fate of 2,4-dichlorophenoxyacetic acid (2,4-D) following oral administration in man. Toxicology 1977, 8, 3-11.

29. Eadsforth, C.V.; Baldwin, M.K. Human dose-Excretion studies with the pyrethroid insecticide, cypermethrin. Xenobiotica 1983, 13, 67-72.

30. Nolan, R.J.; Rick, D.L.; Freshour, N.L.; Saunders, J.H. Chlorpyrifos: Pharmacokinetics in human volunteers. Toxicol. Appl. Pharmacol. 1984, 73, 8-15.

31. Woollen, B.H.; Marsh, J.R.; Laird, W.D.; Lesser, J.E. The metabolism of cypermethrin in man: Differences in urinary metabolite profiles following oral and dermal administration. Xenobiotica 1992, 22, 983-991.

32. Tulve, N.S.; Egeghy, P.P.; Fortmann, R.C.; Whitaker, D.A.; Nishioka, M.G.; Naeher, L.P.; Hilliard, A. Multimedia measurements and activity patterns in an observational pilot study of nine young children. J. Expo. Sci. Environ. Epidemiol. 2008, 18, 31-44. 
33. Tulve, N.S.; Egeghy, P.P.; Fortmann, R.C.; Xue, J.; Evans, J.; Whitaker, D.A.; Croghan, C.W. Methodologies for estimating cumulative human exposures to current-use pyrethroid pesticides. J. Expo. Sci. Environ. Epidemiol. 2011, 21, 317-327.

34. Clayton, A.; Pellizzari, E.D.; Whitmore, R.W.; Quackenboss, J.J.; Adgate, J.; Sexton, K. Distributions, associations, and partial aggregate exposure of pesticides and polynuclear aromatic hydrocarbons in the Minnesota Children's Pesticide Exposure Study (MNCPES). Expo. Anal. Environ. Epidemiol. 2003, 13, 100-111.

35. Clune, A.L.; Ryan, P.B.; Barr, D.B. Have regulatory efforts to reduce organophosphorus insecticide exposures been effective? Environ. Health Perspect. 2012, 120, 521-525.

36. Nishioka, M.G.; Lewis, R.G.; Brinkman, M.C.; Burkholder, H.M.; Hines, C.E.; Menkedick, J.R. Distributions of 2,4-D in air and on surfaces inside residences after lawn applications: Comparing exposure estimates from various media for young children. Environ. Health Perspect. 2001, 109, 1185-1191.

37. Morgan, M.K.; Jones, P.A. Dietary predictors of young children's exposures to current-use pesticides using urinary biomonitoring. Food. Chem. Toxicol. 2013, 62, 131-141.

\section{Appendix}

Table A1. The maximum potential intake dose of a CTEPP child for a pesticide by route when zsing either a $50 \%$ or $100 \%$ default absorption rate value ${ }^{\mathbf{a}}$.

\begin{tabular}{|c|c|c|c|c|c|c|c|}
\hline \multirow[t]{2}{*}{ Class $^{b}$} & \multirow[t]{2}{*}{ Pesticide } & \multicolumn{3}{|c|}{$\begin{array}{l}\text { Maximum Potential Intake Dose at a } \\
50 \% \text { Absorption Rate (ng/kg/day) }\end{array}$} & \multicolumn{3}{|c|}{$\begin{array}{l}\text { Maximum Potential Intake Dose at a } \\
\text { 100\% Absorption Rate (ng/kg/day) }\end{array}$} \\
\hline & & Dietary & Nondietary & Inhalation & Dietary & Nondietary & Inhalation \\
\hline $\mathrm{OC}$ & $\alpha$-Chlordane & 10.1 & 1.51 & 9.37 & 20.2 & 3.02 & 18.7 \\
\hline $\mathrm{OC}$ & $\gamma$-Chlordane & 8.64 & 1.71 & 13.3 & 17.3 & 3.42 & 26.6 \\
\hline $\mathrm{OC}$ & Heptachlor & 15.9 & 6.17 & 118 & 31.8 & 12.3 & 236 \\
\hline OP & Chlorpyrifos ${ }^{\mathbf{c}}$ & 217 & 5.84 & 53.1 & 434 & 11.7 & 106 \\
\hline OP & Diazinon & 40.2 & 16.7 & 380 & 80.4 & 33.4 & 760 \\
\hline PY & $c i s-$ & 2,850 & 143 & 6.84 & 5,700 & 286 & 13.7 \\
\hline PY & $\begin{array}{l}\text { Permethrin } \\
\text { trans- } \\
\text { Permethrin }\end{array}$ & 2,000 & 151 & 8.38 & 4,000 & 302 & 16.8 \\
\hline $\mathrm{AC}$ & 2,4-D & 60.6 & 10.1 & 1.04 & 121 & 20.2 & 2.08 \\
\hline
\end{tabular}

Notes: ${ }^{\text {a }}$ Estimated for pesticides that had $\geq 45 \%$ detects in two or more sampled media;

b Pesticide classes include organochlorine insecticides (OC), organophosphorus insecticides (OP), pyrethroid insecticides (PY), and AC herbicides; AC); ${ }^{\mathbf{c}}$ These data were calculated from Morgan et al. [18].

(C) 2014 by the authors; licensee MDPI, Basel, Switzerland. This article is an open access article distributed under the terms and conditions of the Creative Commons Attribution license (http://creativecommons.org/licenses/by/3.0/). 